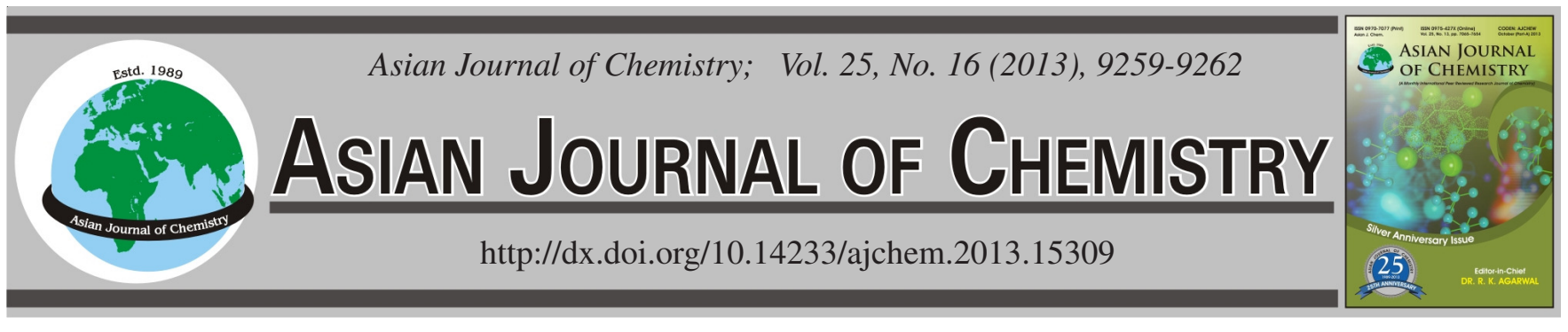

\title{
Effect of $\mathrm{Nano}_{-} \mathrm{TiO}_{2}$ Additives on the Corrosion Performance of Lubricating Oil on Steel 45 Substrates
}

\author{
Shizhao Wang, Xueqin Zhou and DongZhi Liu*
}

Department of Chemical and Technology, Tianjin University, Tianjin 30072, P.R. China

*Corresponding author: Tel: +86 311 81563261; E-mail: shizhaow@163.com

\begin{abstract}
An oleic acid modified $\mathrm{TiO}_{2}$ nanoparticles were synthesized by chemical co-deposition method. The surface morphology, size distribution and structure of the nanoparticles were analyzed by transmission electron microscopy, fourier-transform infrared spectroscopy and laser particle analyzer. The anticorrosion performance of oleic acid- $\mathrm{TiO}_{2}$ was examined by electrochemical techniques. It was found that the $\mathrm{TiO}_{2}$ nanoparticles with average diameter of $44 \mathrm{~nm}$ and combined with oleic acid by covalent bonds, were capable of being dispersed stable in oil, which enabled the nanoparticles to be used as additives in lubricating oil. The results of polarization curves and electrochemical impedance spectroscopy indicated that the addition of oleic acid- $\mathrm{TiO}_{2}$ nanoparticles in lubricating oil decreased the corrosion current density and increased the corrosion resistance of oil film on steel 45 substrates.
\end{abstract}

Key Words: Nano-TiO ${ }_{2}$, Oleic acid, Modification, Corrosion resistance, Electrochemical impedance spectroscopy.

ᄂ - - - - - - - - - - - - - - - - - - - - - - - - - - -

\section{INTRODUCTION}

The application of lubricating oil are the most widespread approach nowadays used for corrosion protection of metallic mechanical parts either in storage or during application by forming effective barrier against corrosive species present in different environments ${ }^{1}$. It is well-known that lubricating oils consist of a mixture of base oil and different additives. Many oil-soluble organic compounds (such as petroleum sulfonates, synthetic alkylbenzene sulfonates, carboxylic acid derivates, oxidized paraffins, alkylated succinic acids, lanolin and 4nonylphenoxyacetic acid) ${ }^{1,2}$ were found to effectively improve the protection efficiency of lubricating oil and used as anticorrosion additives. However, lead, zinc and barium in petroleum sulfonates ${ }^{3}$ and synthetic alkylbenzene sulfonates ${ }^{4}$ caused great harm to the environment and human health. In addition, some of these traditional additives had poor thermo-oxidative stabilities and showed oxidative degradation tendencies under severe conditions of high temperature, extreme pressure and high sliding speed ${ }^{2}$. So researchers keep striving to develop an anticorrosion agent with environment-friendly characteristic and high thermo-oxidative stability.

Nanoparticles had been intensively investigated because of their distinctive physical and chemical properties. Specially $\mathrm{TiO}_{2}$ nanoparticles showed high thermo-oxidative stablility together with good environment-friendly property (without toxic heavy metal element). In addition, Shen's studies had indicated that $\mathrm{TiO}_{2}$ nanoparticle coatings exhibited an excellent corrosion resistance due to a ceramic protective barrier on metal surface and the electrochemical impedance spectroscopy (EIS) measurements provided an explanation to the increased resistance of $\mathrm{TiO}_{2}$ nanoparticles coated $316 \mathrm{~L}$ stainless steel against corrosion ${ }^{5,6}$. Similar results were also obtained by Sathiyanarayanan et al. ${ }^{7}$, Zubillaga et al. ${ }^{8}$ and Shi et al. ${ }^{9}$. Recently, Padhy et al. ${ }^{10}$ evaluated the corrosion resistance of sputter deposited $\mathrm{TiO}_{2}$ on austenitic $304 \mathrm{~L}$ stainless steel in the oxidizing medium of 1 and $8 \mathrm{M}$ nitric acid and showed that an increase in corrosion potential in both test solutions for $\mathrm{TiO}_{2}$ coated specimens. All these results suggest that $\mathrm{TiO}_{2}$ nanoparticles can improve the anticorrosion property by replacing traditional organic anticorrosion additives in lubricating oil.

This study synthesized oil-soluble $\mathrm{TiO}_{2}$ nanoparticles and investigated its effect on the corrosion resistance properties of lubricating oil, thus to evaluate the feasibility of $\mathrm{TiO}_{2}$ nanoparticles as anticorrosion agent. It is expected that this work will be helpful to expanding the range of application of nano$\mathrm{TiO}_{2}$ and improving lubricating oil for corrosion protection of metallic mechanical parts.

\section{EXPERIMENTAL}

The reagents in the experiments such as oleic acid, tetrabutyl titanate $\left[\mathrm{Ti}(\mathrm{OBu})_{4}\right]$, acetone and ethanol were analytical pure reagents. $45 \#$ Transformer oil as the base oil 
of lubricating oil was purchased from Lubricant Company, SINOPEC (China Petroleum \& Chemical Corporation) and used without further treatment. The steel $45(80 \mathrm{~mm} \times 60 \mathrm{~mm}$ $\times 3 \mathrm{~mm}$ ) was used as the substrate of oil film.

Synthesis of nano- $\mathrm{TiO}_{2}$ : The synthesis procedure of oleic acid- $\mathrm{TiO}_{2}$ were as follows: $\mathrm{Ti}(\mathrm{OBu})_{4}$ was added to an amount of oleic acid in a closed vessel under vigorous stirring at room temperature. Then deionized water was dropped slowly into the mixtures while stirring. After reaction was conducted for $4 \mathrm{~h}$ at $60{ }^{\circ} \mathrm{C}$, the reaction mixtures were centrifuged and the deposition were washed repeatedly three times with acetone, ethanol and deionized water to remove excess acid. Then the productions was dried in an oven at $60^{\circ} \mathrm{C}$ for $12 \mathrm{~h}$. Finally the pale yellow powder was the expected oleic acid- $\mathrm{TiO}_{2}$ nanoparticles.

Preparation of test sample oil with oleic acid- $\mathrm{TiO}_{2}$ : The nanoparticles were added to the base oil under the condition of stirring and ultrasonic wave and then the base oil with oleic acid- $\mathrm{TiO}_{2}$ additives used as test sample oil.

Characterization of oleic acid- $\mathrm{TiO}_{2}$ : The FT-IR analysis was performed on an spectrometer (Model Equinox 55 from Brucker). $\mathrm{TiO}_{2}$ nanoparticles were dried in an oven at $40{ }^{\circ} \mathrm{C}$ for $12 \mathrm{~h}$ and then $\mathrm{KBr}$ pellets were prepared with the dried $\mathrm{TiO}_{2}$ nanoparticles. The spectra were collected in the range from $4000-500 \mathrm{~cm}^{-1}$. The morphology and size distribution of the $\mathrm{TiO}_{2}$ nanoparticles was studied by SEM(Model H-9000 from Hitachi) and laser particle analyzer (Model Mastersizer 2000 from Malvern Instruments Ltd., UK).

Evaluation of corrosion resistant properties of oleic acid- $\mathrm{TiO}_{2}$ : The anticorrosion performance of $\mathrm{TiO}_{2}$ on steel 45 substrates was examined by electrochemical analyzer (Model LK2006A from Tianjin Lanlike electrochemical technology Co., Ltd.). The test were carried out in a three-electrode cell including a saturated calomel electrode (SCE), a platinum auxiliary electrode and working electrodes.The working electrodes were steel 45 substrates and were pretreated by the test sample oil (45\# transformer oil with $5 \mathrm{wt}$. $\%$ oleic acid$\mathrm{TiO}_{2}$ ) as follows: electrodes immerged in the sample oil at room temperature for $5 \mathrm{~min}$, then took out and stored in ambient conditions for $16 \mathrm{~h}$.

The electrolyte was $3.5 \mathrm{wt} \% \mathrm{NaCl}$ aqueous solution ( $\mathrm{pH}$ =4.8). The Tafel polarization curves were measured at a sweeping rate of $1 \mathrm{mV} / \mathrm{s}$ in the range from $-1.5 \mathrm{~V}$ to $0.4 \mathrm{~V}$. The applied frequencies of EIS were ranged from $10^{-2}-10^{4} \mathrm{~Hz}$ at the steady open circuit potential (OCP). The experimental data were analyzed by ZSimpwin software and the equivalent circuits were described.

\section{RESULTS AND DISCUSSION}

The untreated $\mathrm{TiO}_{2}$ nanoparticles with many hydroxyl groups were hardly dispersed in lubricating oil. Compounds with a long alkyl chain and polar head such as aliphatic acids ${ }^{11-14}$, coupling agent ${ }^{15}$ and surfactant ${ }^{16}$ could effectively improve their dispersion capacity in lubricating oil. Herein we used oleic acid to modify nano- $\mathrm{TiO}_{2}$ surface, which was designated as oleic acid- $\mathrm{TiO}_{2}$.

Fig. 1 showed the FTIR spectra of oleic acid and oleic acid- $\mathrm{TiO}_{2}$ nanoparticles. Absorptions at 2924, 2856 and 3007 $\mathrm{cm}^{-1}$, corresponding to the stretching vibration of $-\mathrm{CH}_{3},-\mathrm{CH}_{2}-$ and $=\mathrm{CH}-$, showed that there were the abundance of long alkyl chain and double bond between carbon atoms. This revealed that oleic acid was successfully modified on the surface of $\mathrm{TiO}_{2}$ nanoparticles ${ }^{13}$. The characteristic band of carbonyl at $1716 \mathrm{~cm}^{-1}$ in carboxylic acid disappeared and the symmetrical and asymmetrical vibrations of $\mathrm{COO}^{-}$shifted from 1459 and 1400 to 1553 and $1452 \mathrm{~cm}^{-1}$ in Fig. 1b, which indicated that the modifier oleic acid reacted with $\mathrm{TiO}_{2}$ nanoparticles and formed carboxylic acid salt in the nanoparticles. Namely, the surface-modifier film modified on $\mathrm{TiO}_{2}$ nanoparticles not by physically adsorption, but by covalent bonds. In addition, the absorptions of water or hydroxyl groups near $3400 \mathrm{~cm}^{-1}$ is not found in Fig. 1b. It was subsequently concluded that the modifier film could prevent the adsorption of water or hydroxyl groups on the surface of $\mathrm{TiO}_{2}$, which contributed to controlling the particle size and improving the dispersion capacity of nanoparticles in lubricating oil.

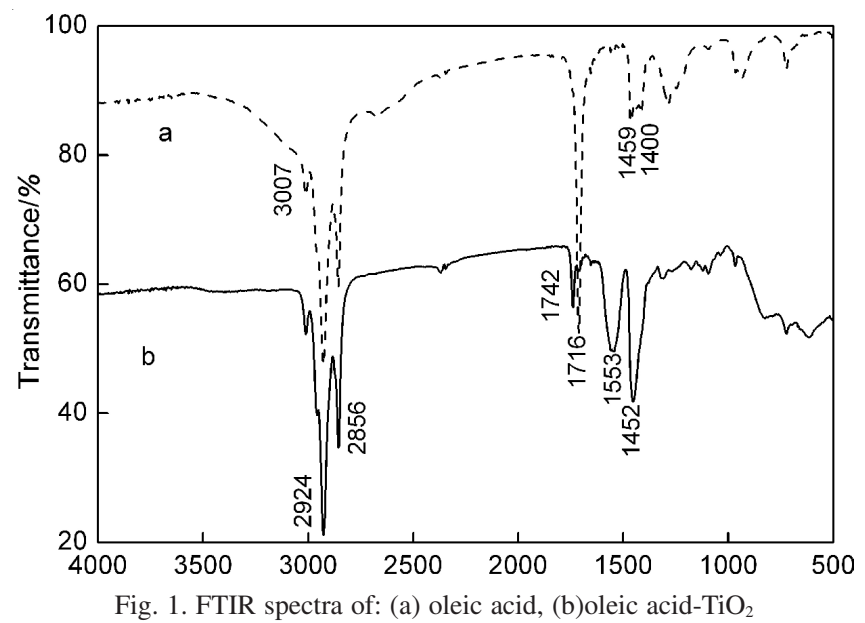

The TEM image in Fig. 2 clearly showed that the single particles were spherical or close to spherical in shape with the average diameter of $44 \mathrm{~nm}$. The maximum size of oleic acid$\mathrm{TiO}_{2}$ particles was also found within $200 \mathrm{~nm}$. After dispersed into base oil, oleic acid- $\mathrm{TiO}_{2}$ particles showed Gaussian distribution, with the average particle diameter of $60 \mathrm{~nm}$ (Fig. 3 ). These indicate that the existence of surface-modifier oleic acid could effectively prevent the agglomeration and make nanoparticles have an excellent dispersion capability in oil, which enables us to study the effects of oleic acid- $\mathrm{TiO}_{2}$ nanoparticles as a potential oil additives on the corrosion performance of lubricating oil.

Fig. 4 showed the influence of nano- $\mathrm{TiO}_{2}$ on corrosion protection of base oil on steel 45 substrate and corresponding electrochemical parameters were given in Table- 1 . The cathodic Tafel curves of the both oil had few changes, which suggested that the cathodic corrosion process was not affected by the presence of oleic acid- $\mathrm{TiO}_{2}$ nanoparticles. The corrosion potential $\left(\mathrm{E}_{\text {corr }}\right)$ showed a little cathodic shift with adding $\mathrm{TiO}_{2}$ nanoparticles and there are obvious passivation region in anodic curves due to the formation of passive film. It could be attributed to oleic acid- $\mathrm{TiO}_{2}$ which is able to inhibit anodic reaction of corrosion process on substrate. From Table-1, the oleic acid- $\mathrm{TiO}_{2}$ nanoparticles as additives decreased the corrosion current density ( $\mathrm{I}_{\text {corr }}$ ) of oil film from 78.523 to $9.258 \mu \mathrm{A} / \mathrm{cm}^{2}$ 


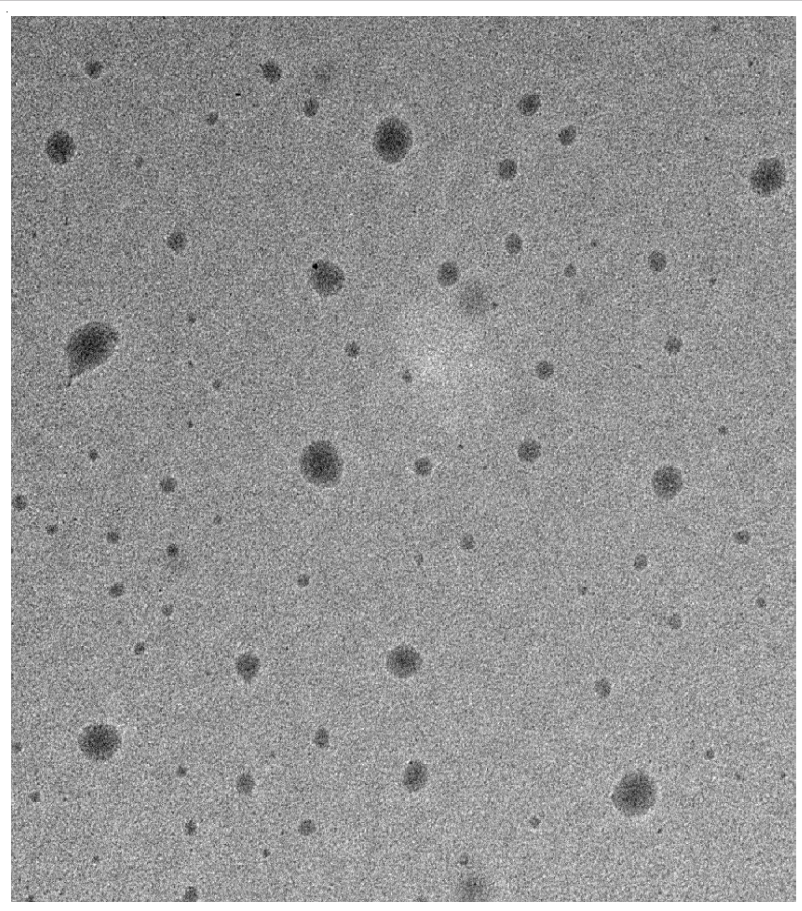

Fig. 2. TEM image of oleic acid- $\mathrm{TiO}_{2}$ nanoparticles

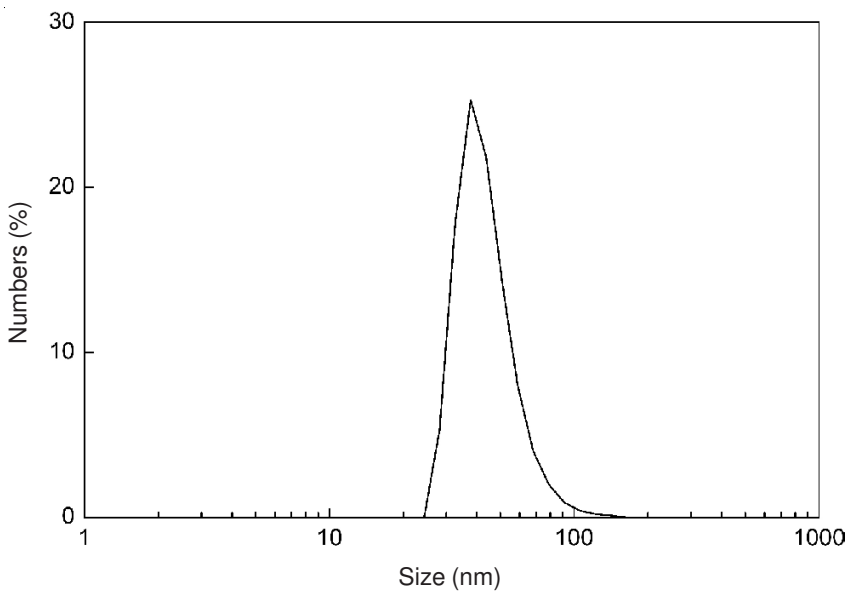

Fig. 3. Size distribution of the oleic acid- $\mathrm{TiO}_{2}$ in base oil

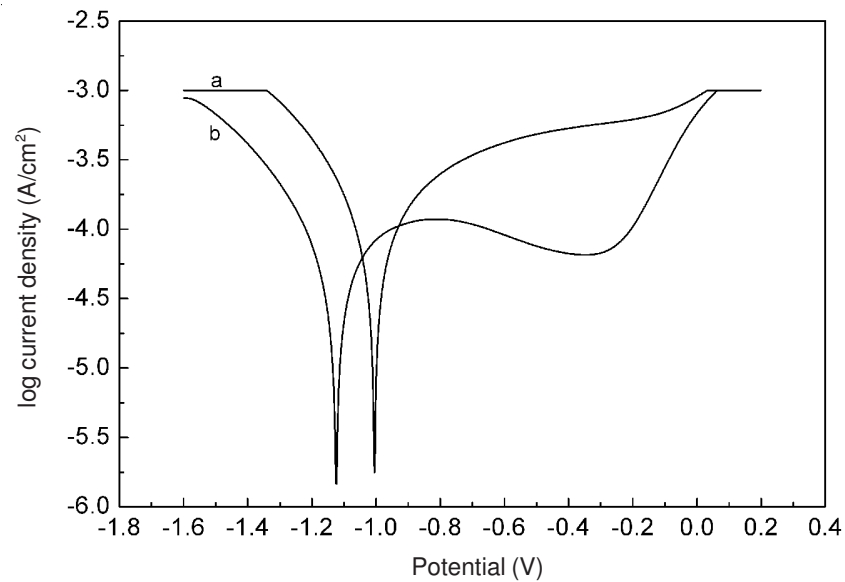

Fig. 4. Tafel polarization curves of (a) base oil and (b) sample oil

and the obtained the corrosion resistance $\left(\mathrm{R}_{\mathrm{p}}\right)$ for oil film increased from 12544 to $122596 \Omega \mathrm{cm}^{2}$ after adding $\mathrm{TiO}_{2}$ nanoparticle. The reduction in the $\mathrm{I}_{\text {corr }}$ by nine times and

\begin{tabular}{cccc}
\multicolumn{4}{c}{ TABLE-1 } \\
\multicolumn{4}{c}{ ELECTROCHEMICAL PARAMETERS } \\
OBTAINED FROM TAFEL CURVES \\
\hline & $\mathrm{I}_{\text {corr }}\left(\mu \mathrm{A} / \mathrm{cm}^{2}\right)$ & $\mathrm{E}_{\text {corr }}(\mathrm{V})$ & $\mathrm{R}_{\mathrm{p}}\left(\Omega / \mathrm{cm}^{2}\right)$ \\
\hline Base oil & 78.523 & -0.985 & 12544 \\
Sample oil & 9.258 & -1.134 & 122596 \\
\hline
\end{tabular}

Notes: (a) the base oil is $45 \#$ transformer oil. Sample oil is $45 \#$ transformer oil with 5 wt. $\%$ oleic acid- $\mathrm{TiO}_{2}$.

improvement in $\mathrm{R}_{\mathrm{p}}$ by ten times implied that oleic acid- $\mathrm{TiO}_{2}$ have good corrosion protective proformance to steel 45 substrate as additives of the lubricating oil.

The EIS measurements had also been carried out on the both oil in $3.5 \% \mathrm{NaCl}$ solution (Fig. 5). Impedance parameters and the equivalent circuit were given in Table-2 and Fig. 7, respectively. In the Nyquist plots (Fig. 5), there was a RC loop in both plots. But the semicircle diameter of capacitance loop in plot(b) was larger than that in plot(a). The capacitance loop with a large value of the resistance(real axis) illustrated that the oil with $5 \%$ oleic acid- $\mathrm{TiO}_{2}$ nanoparticles had an excellent corrosion resistance, which were in accordance with those polarization curves. The Bode diagram of the base oil without oleic acid- $\mathrm{TiO}_{2}$ (Fig. 6a) evidently contained one time constant which could be associated with oil film and two time constant were apparently observed in Bode diagram (Fig. 6b). The one in high frequency $(\mathrm{HF})$ range was related with resistance and capacitance of oil film. The other in low frequency (LF) range was affected by double-layer capacitance associated with the $\mathrm{TiO}_{2}$ particle-rich layer. Fig. 7 showed the equivalent circuit of impedance spectra of the both oil. In this equivalent circuit, Rs represented the solution resistance. $\mathrm{R}_{\mathrm{f}}$ and CPE1 are the oil $1 m$ resistance and capacitance, respectively. CPE2 and $R_{c t}$ were the double layer capacitance and the charge transfer resistance at the metal/ $/ \mathrm{TiO}_{2}$ film interface. Corresponding impedance parameters were obtained by fitting the EIS spectra with the equivalent circuits and listed in Table-2. The corrosion resistance for the oil without $\mathrm{TiO}_{2}$ was $2343 \Omega \mathrm{cm}^{2}$, while that for the oil with oleic acid- $\mathrm{TiO}_{2}$ was $15530 \Omega \mathrm{cm}^{2}$. This means that the corrosion resistance of the base oil has been significantly improved by oleic acid- $\mathrm{TiO}_{2}$ nanoparticles.

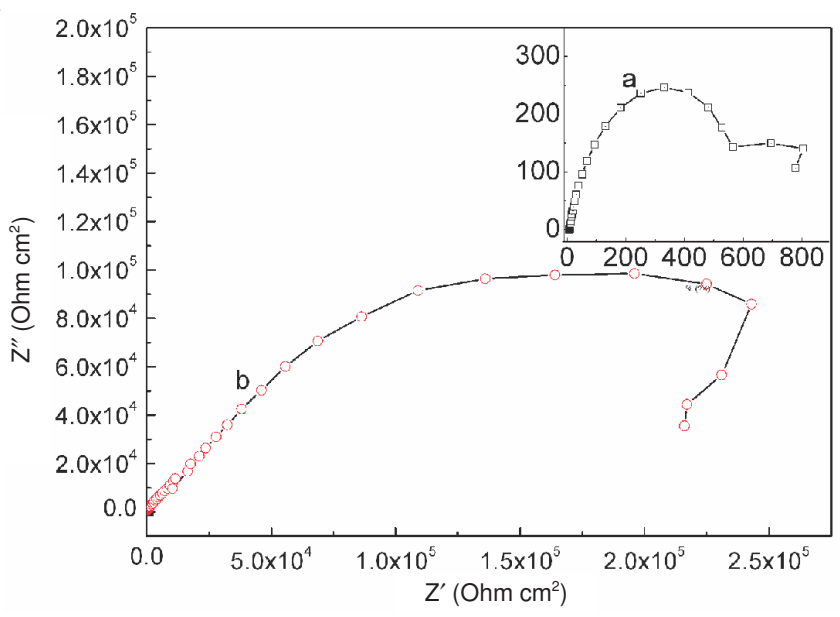

Fig. 5. Nyquist plot for (a) base oil and (b)sample oil 
TABLE-2

EQUIVALENT CIRCUIT PARAMETERS DETERMINED BY MODELING IMPEDANCE SPECTRA IN FIG. $5^{\text {a }}$

\begin{tabular}{cccccccc}
\hline & $\operatorname{Rs}\left(\Omega \mathrm{cm}^{2}\right)$ & $\mathrm{CPE} 1\left(\mathrm{~F} \mathrm{~cm}^{-2}\right)$ & $\mathrm{n} 1$ & $\operatorname{Rf}\left(\Omega \mathrm{cm}^{2}\right)$ & $\mathrm{CPE} 2\left(\mathrm{~F} \mathrm{~cm}^{-2}\right)$ & $\mathrm{n} 2$ & $\operatorname{Rct}\left(\Omega \mathrm{cm}^{2}\right)$ \\
\hline Base oil & 7.265 & $3.491 \times 10^{-5}$ & 1.000 & 2343 & - & - & - \\
Sample oil & 10 & $3.456 \times 10^{-7}$ & 0.740 & 15530 & $1.304 \times 10^{-6}$ & 0.5878 & 368100 \\
\hline
\end{tabular}

Notes: (a) the base oil is $45 \#$ transformer oil. Sample oil is $45 \#$ transformer oil with $5 \mathrm{wt} \% \mathrm{OA}-\mathrm{TiO}_{2}$.

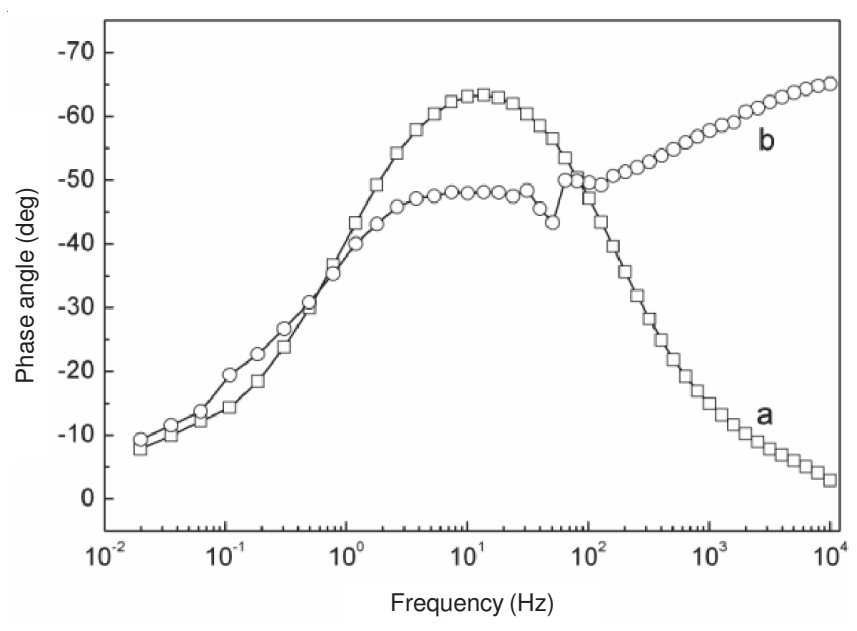

Fig. 6. Bode diagram (a) base oil and (b)sample oil
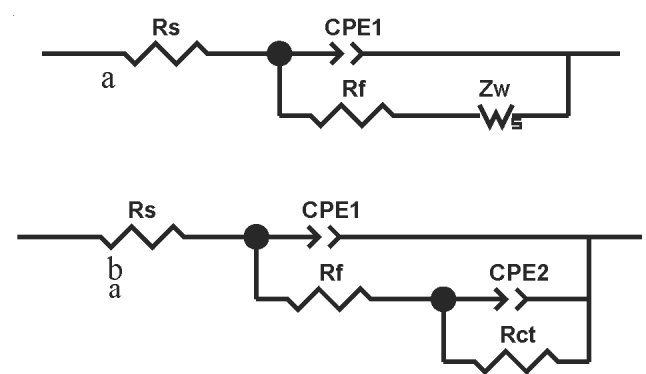

Fig. 7. Equivalent circuit of impedance spectra (a) base oil; (b) sample oil

\section{Conclusion}

$\mathrm{TiO}_{2}$ nanoparticles modified by oleic acid were successfully prepared by the chemical co-deposition method. The covalent bonds between the surface-modifier film and $\mathrm{TiO}_{2}$ nanoparticles were contributed to preventing agglomeration of nanoparticles and controlling the particle size in lubricating oil. The synthesized nanoparticles with an average diameter of $44 \mathrm{~nm}$ could be well dispersed in base oil, which enabled the $\mathrm{TiO}_{2}$ to be used as additives in lubricating oil. The electrochemical measurement showed that because of the formation of passive film, the corrosion potential positively shifts, $\mathrm{I}_{\text {corr }}$ decreases nine times and $R_{p}$ increases above ten times after applying nano- $\mathrm{TiO}_{2}$ as additives of lubricating oil, which suggested the anticorrosive properties of oil film was improved evidently by adding $5 \% \mathrm{TiO}_{2}$. The EIS test also confirmed that the oil-soluble $\mathrm{TiO}_{2}$ nanoparticles had excellent corrosion resistance for metal surface.

\section{REFERENCES}

1. B. Bilitewski, R.M. Darbra and D. Barcelo, Global Risk-Based Management of Chemical Additives I: Production, Usage and Environmental Occurrence, The Handbook of Environmental Chemistry, Springer, Vol. 18, pp. 109-132 (2012).

2. Q.D. Zhong, M. Rohwerder and Z. Zhang, Surf. Coat. Technol., 185, 234 (2004).

3. D. Zhang, P.Y. Zhang, H.K. Zou, G.W. Chu, Wei Wu, Z.W. Zhu, L. Shao and J.F. Chen, Chin. J. Chem. Eng., 18, 848 (2010).

4. V.M. León, C. López, P.A. Lara-Martín, D. Prats, P. Varó and E. González-Mazo, Chemosphere, 64, 1157 (2006).

5. G.X. Shen, Y.C. Chen, L. Lin, C.J. Lin and D. Scantlebury, Electrochim. Acta, 50, 5083 (2005).

6. G.X. Shen, Y.C. Chen and C.J. Lin, Thin Solid Films, 489, 130 (2005).

7. S. Sathiyanarayanan, S.S. Azim and G. Venkatachari, Electrochim. Acta, 52, 2068 (2007).

8. O. Zubillaga, F.J. Cano, I. Azkarate, I.S. Molchan, G.E. Thompson, A.M. Cabral and P.J. Morais, Surf. Coat. Technol., 202, 5936 (2008).

9. H.W. Shi, F.C. Liu, L.H. Yang and E.H. Han, Progr. Org. Coat., 62, 359 (2008).

10. N. Padhy, S. Kamal, R. Chandra, U.K. Mudali and B. Raj, Surf. Coat. Technol., 204, 2782 (2010).

11. H.-J. Song and Z.-Z. Zhang, Tribology Int., 41, 396 (2008).

12. J.H. Qian, X.Y. Yin, N. Wang, L. Liu and J.J. Xing, Appl. Surf. Sci., 258, 2778 (2012).

13. S. Chen and W.M. Liu, Mater. Chem. Phys., 98, 183 (2006).

14. X.J. Xiong, Y.K. Kang, G.B. Yang, S.M. Zhang, L.G. Yu and P.Y. Zhang, Tribol. Lett., 46, 211 (2012).

15. X.H. Li, Z. Cao, Z.J. Zhang and H.X. Dang, Appl. Surf. Sci., 252, 7856 (2006).

16. A.H. Battez, J.E.F. Rico, A.N. Arias, J.L.V. Rodriguez, R.C. Rodriguez and J.M.D. Fernandez, Wear, 261, 256 (2006). 